\title{
Chronic Social Stress Alters Levels of Corticotropin-Releasing Factor and Arginine Vasopressin mRNA in Rat Brain
}

\author{
David S. Albeck, ${ }^{4}$ Christina R. McKittrick, ${ }^{1}$ D. Caroline Blanchard, ${ }^{2}$ Robert J. Blanchard, ${ }^{2}$ Julia Nikulina, ${ }^{2}$ \\ Bruce S. McEwen, ${ }^{1}$ and Randall R. Sakai ${ }^{3}$ \\ ${ }_{1}^{1}$ Rockefeller University, New York, New York 10021, 2University of Hawaii, Honolulu, Hawaii 96822, 3 University of \\ Pennsylvania, Philadelphia, Pennsylvania 19104, and ${ }^{4}$ University of Colorado Health Sciences Center, Denver, Colorado 80262
}

In the visible burrow system model of chronic social stress, male rats housed in mixed-sex groups quickly form a dominance hierarchy in which the subordinates appear to be severely stressed. A subgroup of subordinates have an impaired corticosterone response after presentation of a novel restraint stressor, leading to their designation as nonresponsive subordinates. To examine the mechanism underlying the blunted corticosterone response in these animals, in situ hybridization histochemistry was used to quantify corticotropin-releasing factor (CRF) and arginine vasopressin (AVP) mRNA expression in the brain. In two separate visible burrow system experiments, the nonresponsive subordinates expressed a significantly lower average number of CRF mRNA grains per cell in the paraventricular hypothalamic nucleus compared with stress-responsive subordinates, dominants (DOM), or cage-housed control (CON) rats. The number of CRF mRNA labeled cells was also significantly lower in nonresponders than in responsive subordinates or DOM. In the central amygdala, CRF mRNA levels were increased in both groups of subordinates compared with CON rats, whereas responsive subordinates exhibited higher levels than the DOM rats as well. AVP mRNA levels did not vary with behavioral rank in any subdivision of the paraventricular hypothalamic nucleus. In the medial amygdala, the number of cells expressing AVP mRNA was significantly greater in CON rats compared with both groups of subordinates, although the average number of AVP mRNA grains per cell did not vary with rank. In addition, the number of AVP-positive cells significantly correlated with plasma testosterone level.

Key words: stress; corticosterone; CRF; AVP; in situ hybridization; neuropeptide
Adrenal steroids such as corticosterone (CORT) play an important role in mitigating the adverse effects of stress; however, chronic activation of the hypothalamic-pituitary-adrenal (HPA) axis may have pathological consequences for the animal. Exposure to chronic stress has been shown to alter HPA axis responses to subsequent stressors (Caggiula et al., 1989) as well as to alter basal HPA activity (Ottenweller et al., 1989, 1992). In addition, stress suppresses testosterone secretion in both rodents and primates, including man (Taché et al., 1980; Armario and Castellanos, 1984; Wheeler et al., 1984; Sapolsky, 1985). Prolonged increases in glucocorticoids elicited by chronic stress or through exogenous administration can also affect brain physiology (Diamond et al., 1992; Pavlides et al., 1995), neuronal morphology and viability (Sapolsky et al., 1985; Woolley et al., 1990; Magariños and McEwen, 1995), and behavior (Katz et al., 1981; Weiss et al., 1981; Garcia-Marquez and Armario, 1987).

Many of these stress-related changes are readily apparent in the visible burrow system (VBS) model of chronic social stress. A dominance hierarchy quickly forms among male rats housed in mixed-sex groups in a complex environment for $14 \mathrm{~d}$. The subordinate males show sustained elevations in plasma CORT, profound weight loss, impaired testosterone production, thymus involution, and adrenal hypertrophy (Blanchard et al., 1993). In addition, although all animals have robust CORT responses to

Received Aug. 21, 1996; revised April 2, 1997; accepted April 8, 1997.

This work was supported by National Science Foundation Grants IBN95-11349 (D.C.B., R.J.B., R.R.S.) and MH41256 (B.S.M.).

Correspondence should be sent to Prof. David Albeck, University of Colorado Health Sciences Center, 4200 East 9th Avenue, Department of Basic Sciences and Oral Research, Campus Box C286, Denver, CO 80262.

Copyright (C) 1997 Society for Neuroscience $0270-6474 / 97 / 174895-09 \$ 05.00 / 0$ stress before group housing, after 2 weeks in the VBS, a subgroup of subordinates show an impairment in their ability to produce the characteristic rise in plasma CORT when presented with a novel stressor (Blanchard et al., 1993).

The physiological basis for the attenuated HPA responsiveness in these subordinate rats is currently unclear. The lack of a stress-induced rise in CORT in the nonresponsive subordinates (NRS) may be attributable to a functional breakdown at some level of the HPA axis. To determine whether the dysfunction of the HPA axis of the NRS rats is attributable to alterations in the hypothalamic corticotropic systems, we examined the effect of chronic social stress on corticotropin-releasing factor (CRF) and arginine vasopressin (AVP) mRNA levels in paraventricular hypothalamic nucleus (PVN).

In addition, we investigated CRF and AVP mRNA in extrahypothalamic sites such as the amygdala, which sends projections to other limbic structures. In these circuits, the neuropeptides may be involved in some of the behavioral changes observed in the VBS animals, because central CRF projections have been shown to mediate stress-related behaviors in rats (Makino et al., 1994), whereas central AVP projections are involved with aggressive (Koolhaas et al., 1990; Compaan et al., 1993) and sexual (Winslow et al., 1993; Minerbo et al., 1994) behaviors in rodents.

\section{MATERIALS AND METHODS}

Experimental procedure. The VBS apparatus and experimental protocol has been described previously in detail (Blanchard and Blanchard, 1990). In brief, the burrow system is comprised of an open field area $(85 \times 65$ $\mathrm{cm})$ connected to a series of tunnels and two small compartments. Food and water are available ad libitum in the open field area, which is illuminated on a 12:12 hr light/dark schedule, whereas the remainder of the apparatus is shielded from the light. 


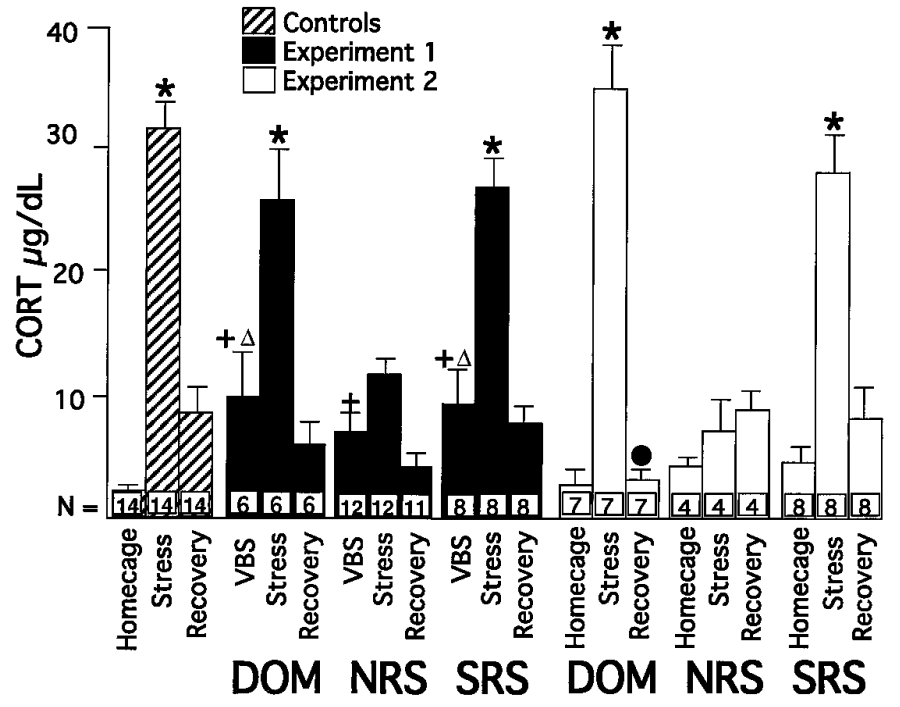

Figure 1. Plasma CORT responses to a novel restraint stressor in animals from both VBS experiments. In experiment 1, prestress CORT was measured in tail blood samples taken immediately after removal from the VBS; in experiment 2, prestress samples were taken after animals had been removed from the VBS and placed in their home cages for $1 \mathrm{hr}$. In both studies, stress CORT levels were measured after $1 \mathrm{hr}$ in a plexiglass restrainer, and recovery CORT was measured $1 \mathrm{hr}$ after termination of the stressor. Recovery CORT level was significantly lower for the DOM group in experiment 2 than the CON rat recovery value. CON animals were combined from both studies. DOM, Dominant rats; NRS, nonresponder subordinate rats; $S R S$, stress-responsive subordinate rats. Values represent the mean $\pm \mathrm{SEM} ;{ }^{*} p<0.0001$ versus NRS rats; ${ }^{+} p<0.05$ versus CON rats; ${ }^{\Delta} p<0.05$ versus the DOM group in experiment 2 .

Data from two VBS experiments are presented. Experimental procedures were similar in the two studies. In both experiments, colonies of five male and two female Long-Evans rats were housed in a VBS for $14 \mathrm{~d}$. In experiment 1 , control (CON) rats were either individually housed or housed in male-female pairs, whereas in experiment 2, all CON rats were housed in male-female pairs. CON males were age- and weight-matched to a specific colony and maintained on the same light/dark cycle as the VBS colonies. In experiment 1 , male rats were removed from the VBS on days $3,6,8$, and 10 , then weighed and returned to their individual home cages for $6 \mathrm{hr}$ during the light phase to allow free access to food and water. In experiment 2, rats were removed from the VBS daily and placed in their home cages for $4 \mathrm{hr}$. Pair-housed CON males were separated from the females during this time.

Behavior was monitored during the dark phase of the light/dark cycle using a video camera and infrared light source. A single dominant was identified for each colony based on wound pattern, body weight, and behavioral analysis of specific offensive and defensive behaviors and time spent in the open field area.

On day 14, animals were removed from the VBS in the early part of the light cycle. In experiment 1 , male rats were taken directly from the VBS and placed in restraint tubes, and a blood sample was quickly drawn from the tail to determine plasma CORT levels in the context of the VBS. In experiment 2, males were placed in their home cages for $1 \mathrm{hr}$ before the initial sampling to determine basal CORT levels outside the VBS. In both experiments, the animals remained in the restrainer for $1 \mathrm{hr}$, after which another blood sample was drawn for measurement of stress levels of CORT. A third sample was taken $1 \mathrm{hr}$ after the animals had been removed from the restrainers and returned to their home cages.

Prestress, stress, and recovery levels of CORT were determined by radioimmunoassay using rabbit antiserum raised against CORT-21hemisuccinate BSAS (B21-42, Endocrine Sciences, Calabasas, CA). Assay sensitivity was $10 \mathrm{pg}$, and the intra-assay coefficient of variability was 2-5\%. Plasma testosterone levels were measured using a Coat-a-Count RIA kit (Diagnostic Products, Milford, MA) following the manufacturer's directions.

The subordinate rats showed a bimodal distribution of their stress CORT levels, with some animals showing an increase in CORT compa- rable with DOM and CON rats, whereas others had little or no increase in CORT at all. Subordinates were defined as nonresponders if they failed to show an increase of at least $10 \mu \mathrm{g} / \mathrm{dl}$ CORT over the mean prestress CORT level of all subordinates. Statistical analysis (ANOVA followed by Fisher's LSD post hoc test) of the CORT data was performed using the Statview statistical program.

Animals were killed by decapitation on the day after the restraint stress test. Brains were quickly removed, frozen on powdered dry ice, and stored at $-70^{\circ} \mathrm{C}$.

In situ hybridization. The in situ hybridization technique used has been described previously in detail (Albeck et al., 1994). Sixteen micrometer coronal sections were cut on a cryostat and thaw-mounted onto gelatincoated slides. Sections were kept at $-70^{\circ} \mathrm{C}$ until use. Slides were brought to room temperature in a dessicator, fixed in $4 \%$ formaldehyde solution, rinsed in PBS, acetylated, dehydrated in a series of ethanol baths, delipidized in chloroform, and dried.

In situ hybridization histochemistry for CRF was performed on sections from both experiments 1 and 2 using a 48-mer cDNA oligoprobe corresponding to amino acids 22-37 of preprocorticotropin-releasing hormone (Thompson et al., 1987). In situ hybridization for AVP was performed on sections from experiment 2 using a 27-mer (AVP) directed against amino acids 110-118 of rat prepropressophysin (Schmale et al., 1983). The $3^{\prime}$ end was labeled with $\left[{ }^{35}\right.$ S $]$ dATP using terminal transferase (Boehringer Mannheim, Indianapolis, IN) following the manufacturer's instructions. Labeled probe was purified over a Nuctrap column (Stratagene, La Jolla, CA). Typical activity was $3-5 \times 10^{5} \mathrm{cpm} / \mu \mathrm{l}$.

Sections were hybridized in a solution of $50 \%$ formamide $/ 50 \%$ hybridization buffer ( $600 \mathrm{~mm} \mathrm{NaCl}, 80 \mathrm{~mm}$ Tris- $\mathrm{HCl}, 4 \mu \mathrm{M}$ EDTA, $0.1 \%$ sodium pyrophosphate, $0.2 \%$ SDS, $0.2 \mathrm{mg} / \mathrm{ml}$ heparin, and $10 \%$ dextran sulfate) at $42^{\circ} \mathrm{C}$ overnight. Subsequently, coverslips were floated off in $1 \times \mathrm{SSC}$, and the tissue was washed four times for $15 \mathrm{~min}$ each at $45^{\circ} \mathrm{C}$ in baths containing $50 \%$ formamide and $50 \% 2 \times$ SSC. Slides were then rinsed in $1 \times \mathrm{SSC}$ for $1 \mathrm{hr}$ at room temperature, dipped in $\mathrm{ddH}_{2} \mathrm{O}$, dipped in $70 \%$ EtOH, and dried.

Image analysis and grain-counting. Slides were exposed to Kodak (Rochester, NY) XAR x-ray film, and relative optical density was measured by computer-assisted densitometry (Imaging Research, M4 version, St. Catharine's, Ontario). For each animal, an average optical density was obtained, consisting of at least three anatomically matched brain slices.

Slides were then dipped in Kodak NTB2 emulsion and exposed for varying lengths of time [ $29 \mathrm{~d}$ for CRF in the PVN, $11 \mathrm{~d}$ for AVP in the PVN, $45 \mathrm{~d}$ for CRF in the central amygdala (ACE), and $50 \mathrm{~d}$ for AVP in the amygdaloid nucleus (AME)]. Emulsions were developed and counterstained with cresyl violet to histologically verify anatomical location.

Two methods of grain-counting were used to quantify CRF and AVP mRNA expression levels in the medial PVN. In both methods, four sections per animal on two different slides corresponding to approximately $-1.8 \mathrm{~mm}$ from bregma (Paxinos and Watson, 1982) were counted bilaterally. Background was subtracted from each reading.

The first method was used to measure CRF mRNA in experiment 1 and to measure AVP mRNA in experiment 2. In the first method, a $300 \times$ $260 \mu \mathrm{m}$ field of the medial parvocellular region parallel to the third ventricle was digitized for analysis under $20 \times$ magnification. The number of grains $>50$ cells in this field was quantified using an annulus $35 \mu \mathrm{m}$ in diameter. Average parvocellular cell diameter was $20 \mu \mathrm{m}$. An average of 10 annulus readings over portions of the field that did not contain cells was used to calculate the background value for each individual PVN.

The second grain-counting method was used to quantify CRF mRNA grains in experiment 2. This method consisted of digitizing the same region of the medial PVN and counting the total number of grains over this field. This number was then divided by the total number of cells present in the field. This approach yielded slightly lower, but very comparable, average grains per cell compared with the first method. Background values were obtained by measuring the total number of grains in the same size field in cerebral cortex, an area of brain that expresses low CRF mRNA levels. The number of CRF mRNA labeled cells in experiment 2 was not calculated, because the grain-counting method used in experiment 2 did not provide this measure.

For counting AVP mRNA grains in the AME, three sections per animal were quantified bilaterally. An annulus $35 \mu \mathrm{m}$ in diameter was centered around each labeled cell. Only labeled cells $(3 \times$ background $)$ were counted. Background was obtained by averaging 10 annulus placements over areas devoid of cells and was subtracted from each cell.

Relative optical density readings and grain-counting procedures were performed with the experimenter blind to the behavioral ranking of the 

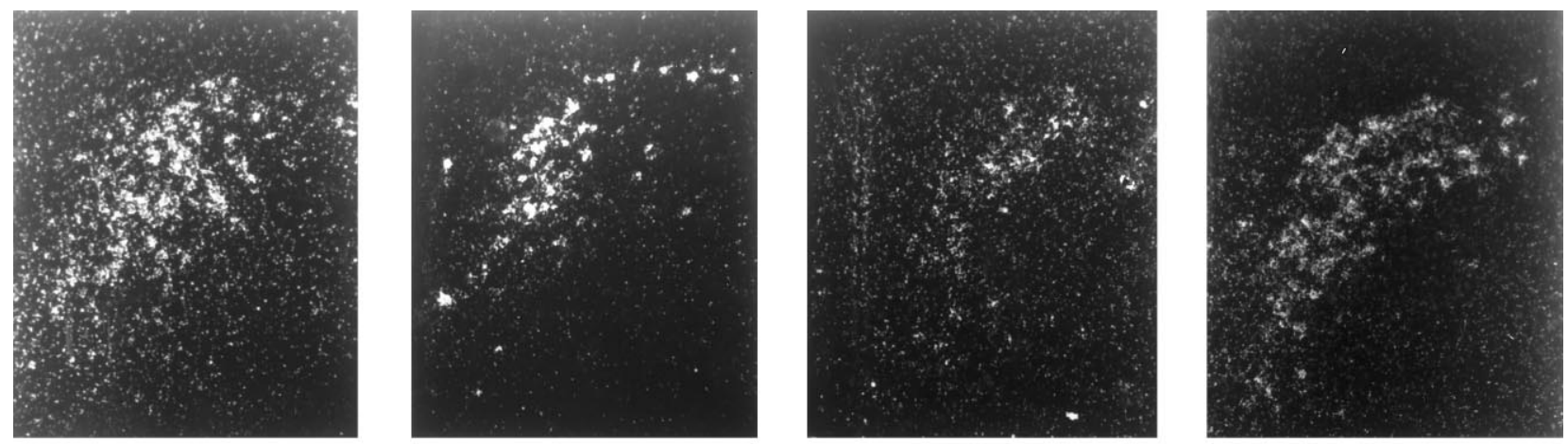

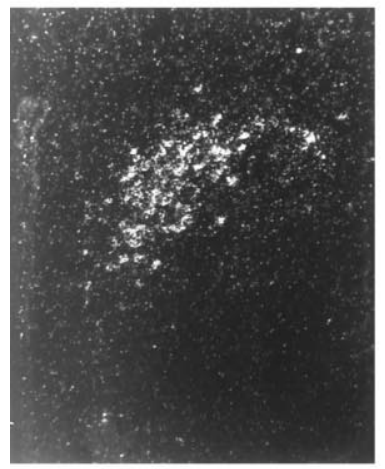

Control (Con)

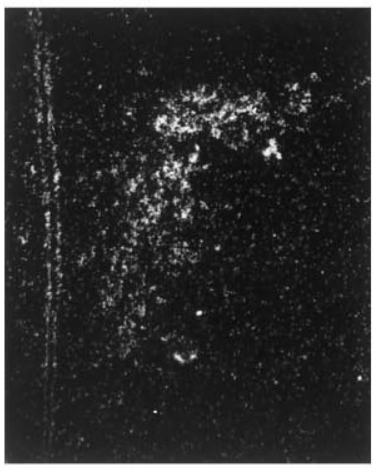

Dominant (Dom)

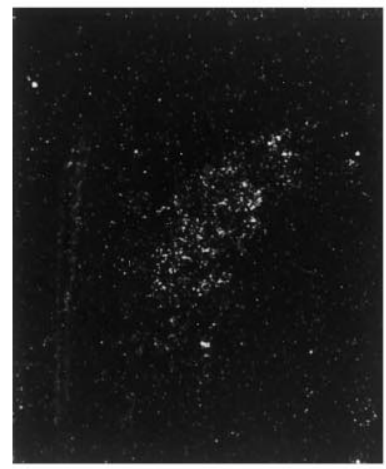

Non-Responder Subordinate (NRS)

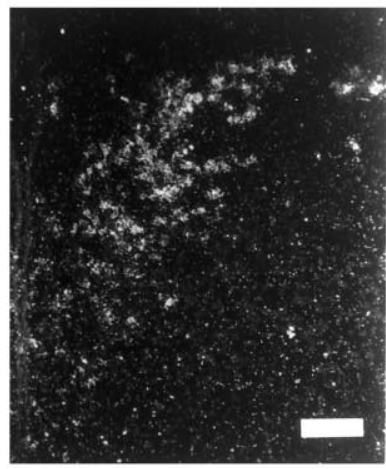

\section{Subordinate Responder (SRS)}

Figure 2. Dark-field photographs of CRF mRNA expression in the PVN of the hypothalamus. In both experiment 1 (top row) and experiment 2 (bottom row), NRS rats exhibit significantly lower levels of CRF mRNA compared with DOM and SRS rats. In experiment 2, NRS rats also have significantly less CRF mRNA compared with CON rats. Scale bar, $100 \mu \mathrm{m}$.

subjects. Data were analyzed using one-way ANOVA followed by Fisher's LSD post hoc test or by simple regression (Statview program).

\section{RESULTS}

\section{Stress responses}

Prestress, stress, and recovery plasma CORT levels from both experiments are presented in Figure 1. There were no differences between the single and pair-housed CON rats from both experiments, thus these data have been grouped together. In experiment 1, blood was drawn immediately on removal from the VBS for the prestress "VBS" CORT measurement, whereas in experiment 2, rats were removed from the VBS and placed into their home cages for $1 \mathrm{hr}$ before blood was drawn ("Homecage" CORT). In experiment 1, "VBS" plasma CORT levels were significantly higher in the dominant (DOM), NRS, and stress-responsive subordinate (SRS) rats compared with CON "Homecage" levels $\left({ }^{+} p<0.05\right)$. The DOM and SRS groups in experiment 1 also exhibited significantly higher levels of CORT at the prestress "VBS" time point than when compared with the prestress "Homecage" level of the DOM group in experiment 2. All except NRS rats showed the characteristic increase in plasma CORT when exposed to $1 \mathrm{hr}$ novel restraint stress $\left({ }^{*} p<0.05\right.$ vs NRS rats). The DOM group in experiment 2 had significantly lower CORT levels at the recovery time point than did CON rats at the recovery time point $(\bullet p<0.05)$.

\section{CRF mRNA in PVN}

Dark-field photographs of CRF mRNA expression in the PVN are shown in Figure 2; the top row of photographs in Figure 2 illustrates examples of CRF mRNA levels in experiment 1, whereas the bottom row of photographs is from experiment 2 . The population results are presented in Figure 3. In experiment 1 (Fig. 3A), NRS rats exhibited a statistically lower average number of CRF mRNA grains per cell than both the DOM and SRS rats $\left(F_{(3,27)}=3.58, p<0.05\right)$, whereas in experiment 2 (Fig. $3 B$ ), NRS rats expressed significantly fewer CRF mRNA grains per cell than did DOM, SRS, and CON rats $\left(F_{(3,24)}=\right.$ $5.76, p<0.005)$. In experiment 1 , the average number of CRF mRNA-labeled cells in the PVN was significantly higher in SRS than in NRS and CON rats, whereas DOM also had a higher number of labeled cells than did NRS rats (Figure $3 C)\left(F_{(3,27)}\right.$ $=6.98, p<0.001)$.

\section{CRF mRNA in the ACE}

The dark-field photographs in Figure 4 illustrate examples of CRF mRNA expression within the ACE. Population results show that SRS and NRS rats have statistically higher levels of CRF mRNA than do CON rats (Fig. 5), whereas SRS rats also had a higher level than did DOM rats $\left(F_{(3,22)}=5.99, p<0.05\right)$. 

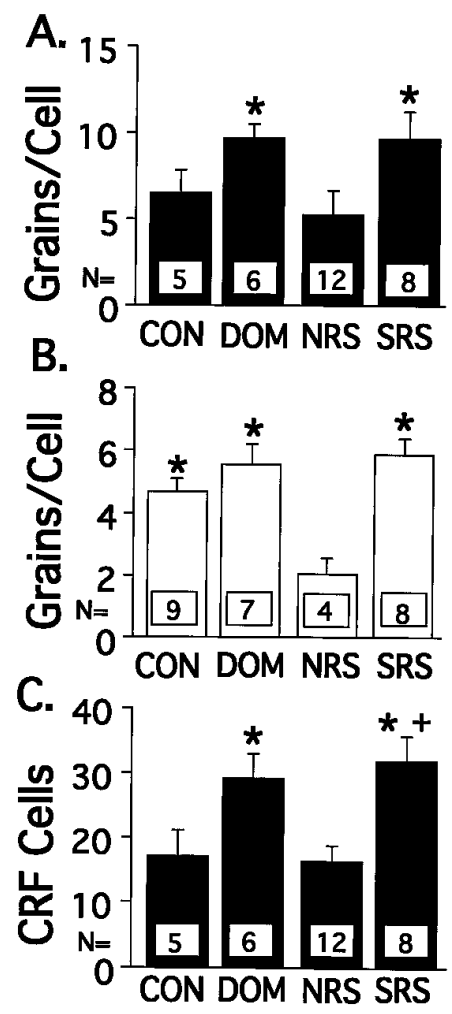

Figure 3. CRF mRNA expression in the PVN of the hypothalamus of VBS animals. $A$, CRF mRNA in experiment 1 expressed as grains per cell. $B$, CRF mRNA in experiment 2 expressed as grains per cell. $C$, Number of CRF mRNA-labeled cells in experiment 1 . Values represent the mean $\pm \mathrm{SEM} ;{ }^{*} p<0.05$ versus NRS; ${ }^{+} p<0.05$ versus CON.

\section{AVP mRNA in PVN}

As shown in Table 1 (top row), relative optical density measures of AVP mRNA levels in the lateral magnocellular PVN did not vary across behavioral rank. Grain-counting was used to quantify AVP mRNA levels in the medial parvocellular PVN. As seen in the second and third rows, respectively, of Table 1, neither the average number of AVP mRNA grains per cell nor the number of AVP mRNA labeled cells in the medial parvocellular PVN differed significantly across ranks.

\section{AVP mRNA in the AME}

Examples of AVP mRNA expression in the AME are shown in the dark-field photographs of Figure 6. The average number of AVP mRNA grains per cell did not differ as a function of behavioral rank in the AME (Fig. 7A). However, the average number of AVP mRNA-labeled cells in the AME did vary with behavioral rank. Post hoc tests revealed that NRS and SRS rats had a significantly lower number of AVP mRNA-positive cells than did CON rats (Fig. $7 B)(p<0.05)$. In addition, there was a significant positive correlation between the number of AVP mRNA-positive cells in the AME and plasma testosterone level (Fig. 8) $(Y=$ $\left.0.54 \times+11.05, r^{2}=0.153, F_{(1,24)}=4.32, p<0.05\right)$.

\section{DISCUSSION}

Fourteen days of mixed-sex housing in a VBS leads to a variety of stress-related changes in the behavior (Blanchard and Blanchard, 1990), endocrine function (Blanchard et al., 1993, 1995), and neurochemistry (Chao et al., 1993; McKittrick et al., 1995, Watanabe et al., 1995) of the male rats. In all animals, total plasma

\begin{tabular}{|c|c|c|c|c|}
\hline & $\mathrm{CON}$ & DOM & NRS & SRS \\
\hline \multirow{2}{*}{$\begin{array}{l}\text { Magnocell } \\
\text { ROD }\end{array}$} & $\times=0.780$ & $\times=0.786$ & $\times=0.820$ & $\times=0.775$ \\
\hline & $\mathrm{SD}=0.074$ & $\mathrm{SD}=0.0667$ & $\mathrm{SD}=0.073$ & $\mathrm{SD}=0.064$ \\
\hline \multirow{2}{*}{$\begin{array}{l}\text { Parvocell } \\
\text { grains/cell }\end{array}$} & $\times=9.09$ & $\times=10.84$ & $\times=8.69$ & $\times=11.06$ \\
\hline & $\mathrm{SD}=2.46$ & $\mathrm{SD}=2.79$ & $\mathrm{SD}=2.70$ & $\mathrm{SD}=2.87$ \\
\hline \multirow{2}{*}{$\begin{array}{l}\text { Parvocell } \\
\quad \text { \# Cells }\end{array}$} & $x=27.53$ & $x=34.12$ & $\times=25.81$ & $\times=30.89$ \\
\hline & $\mathrm{SD}=7.67$ & $\mathrm{SD}=8.02$ & $\mathrm{SD}=5.85$ & $\mathrm{SD}=7.27$ \\
\hline
\end{tabular}

$\overline{\text { AVP mRNA data obtained from experiment 2; values are mean }(\times) \pm \text { SD. Top row, }}$ Relative optical densities (ROD) for AVP mRNA levels in the lateral magnocellular PVN. Middle row, Average number of grains expressed per cell in the medial PVN. Bottom row, Average number of AVP mRNA-labeled cells in the medial PVN. No significant differences in AVP mRNA were found across behavioral groups.

CORT levels measured immediately after removal from the VBS are elevated compared with levels in cage-housed CON rats, suggesting tonic activation of the HPA axis within the VBS environment.

In addition, a subgroup of subordinates did not exhibit the expected increase in plasma CORT when presented with the novel stressor of restraint. Compared with VBS rats, which showed the stress-induced increase in plasma CORT, NRS rats showed a deficit of CRF mRNA, but not of AVP mRNA, in the PVN. The NRS rats appear to be the most severely stressed in the VBS model, because they show the greatest degree of body weight loss and adrenal hypertrophy; the NRS rats also have the lowest levels of testosterone and CORT-binding globulin compared with the other VBS groups (McKittrick et al., 1994). Recent evidence indicates that the NRS characteristics develop gradually over the $14 \mathrm{~d}$ period in the VBS rats, suggesting that they are manifestations in individual rats of their response to the chronic stress situation (our unpublished observations).

NRS and SRS rats show similarities in neuropeptide mRNA levels in the amygdala in contrast to in the PVN. In the amygdala, CRF mRNA expression was elevated in both groups of subordinates compared with that in the CON rats. SRS rats also showed a higher level of CRF mRNA than did DOM rats; the difference between NRS and DOM rats did not reach statistical significance, most likely because of the limited number of animals in the NRS group. The elevated CRF mRNA levels may be the result of the direct effect of CORT on CRF gene expression, because other researchers have reported that plasma CORT correlates positively with CRF mRNA in the ACE, and negatively with CRF mRNA in the PVN (Makino et al., 1994).

CRF and AVP act as neuromodulators in limbic circuits originating in the amygdala. The CRF projections originating in the amygdala are believed to play an important role in the expression of stress-induced behaviors distinct from the effects of CRF in the PVN (Makino et al., 1994). The behavioral effects of central administration of CRF mimic those seen in response to stress, such as place aversion, increased grooming and locomotor activity, and decreased sexual activity and sleeping (Sirinathsinghji et al., 1983; Sherman and Kalin, 1986; Berridge and Dunn, 1987; Lee et al., 1987; Cador et al., 1992). In stressed animals, CRF administration potentiates these behaviors (Britton et al., 1982), whereas CRF antagonists administered intracerebroventricularly or to the ACE can block the behavioral effects of stress (Berridge and Dunn, 1987; Kalin and Takahashi, 1990; Swiergiel et al., 1993). Enhanced CRF expression in the ACE of the subordinates 


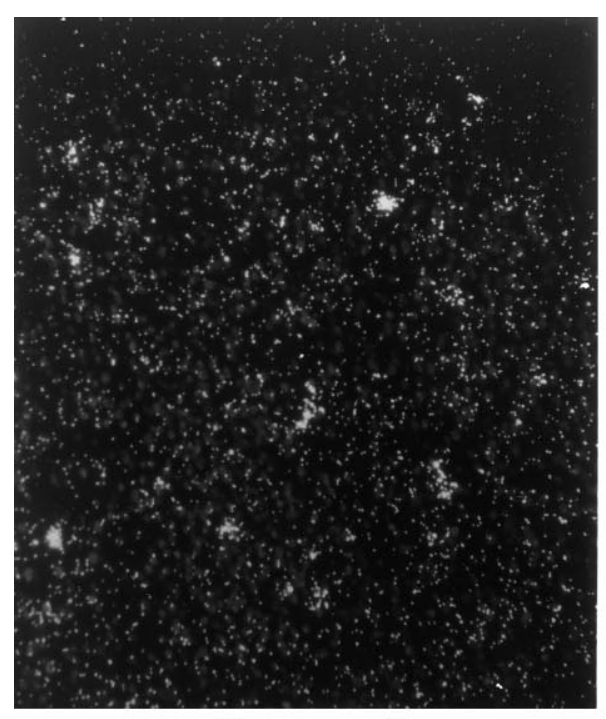

Control

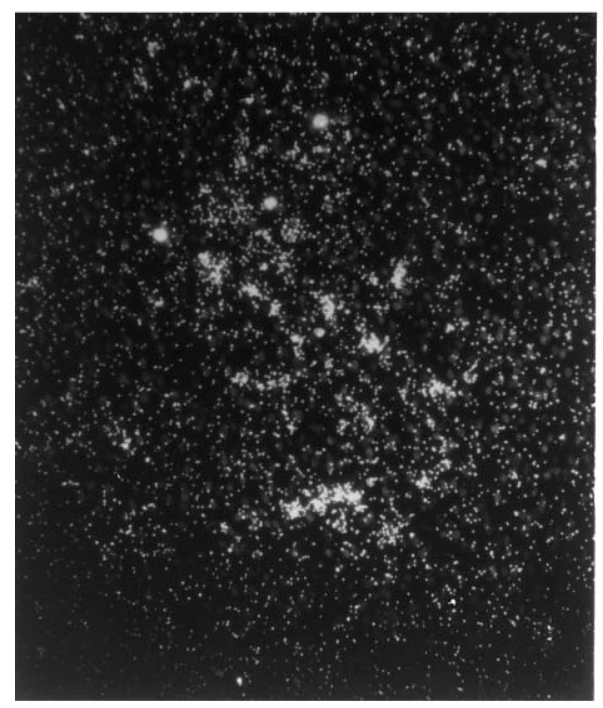

\section{Non-Responder Subordinate}

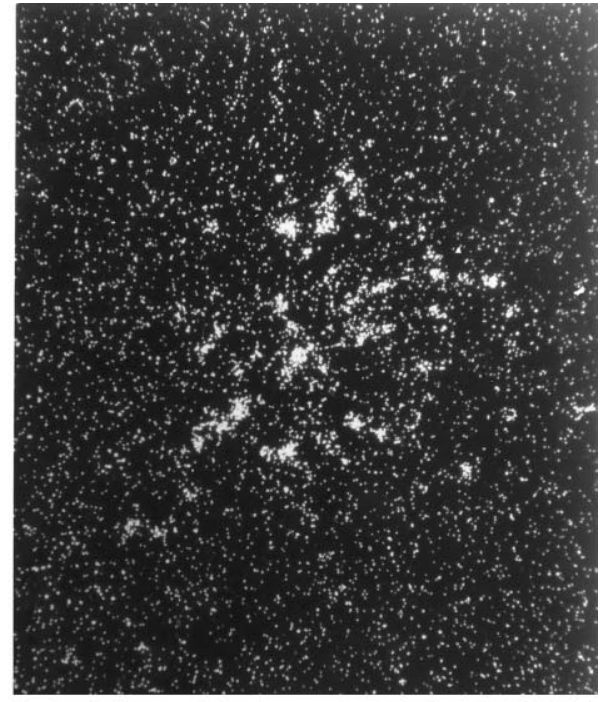

Dominant

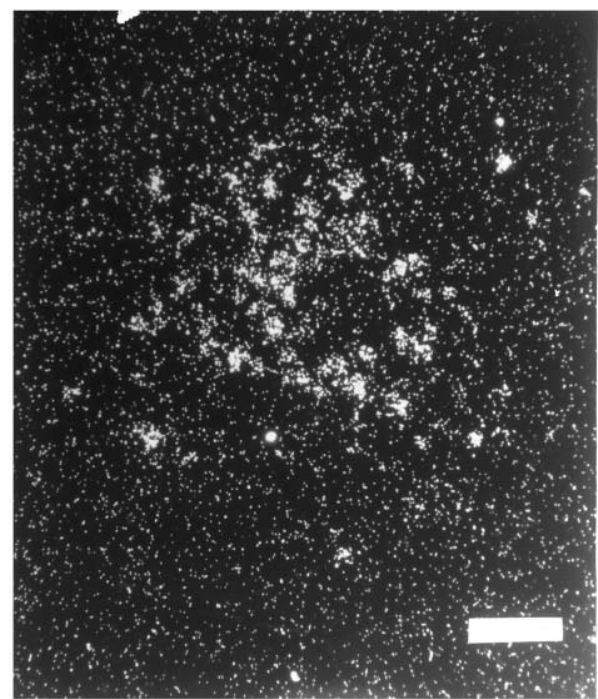

\section{Subordinate Responder}

Figure 4. Dark-field photographs of CRF mRNA expression in the ACE. NRS and SRS rats exhibit significantly higher levels of CRF mRNA than do CON rats. Additionally, SRS rats show greater CRF mRNA expression than DOM rats. Scale bar, $50 \mu \mathrm{m}$. likely contributes to the stress-induced behavioral changes described previously in this model (Blanchard and Blanchard, 1990).

AVP mRNA expression in the AME also varied as a function of behavioral rank, with fewer cells expressing AVP in the two subordinate groups compared with $\mathrm{CON}$ rats. There was also a significant positive correlation between the number of cells expressing AVP and plasma testosterone levels, suggesting that the decrease in AVP is related to the suppression of testosterone in these animals. Although the type II glucocorticoid receptor agonist dexamethasone has been shown to suppress AVP mRNA levels in AME, gonadal steroids seem to be more important in the regulation of AVP in this region, because the decrease is contingent on a concomitant suppression of testosterone levels (Urban et al., 1991). Testosterone has also be shown to play a key role in the regulation of extrahypothalamic AVP expression in other models, because castration leads to a decrease in AVP mRNA and immunoreactivity, an effect that can be reversed by testoster-

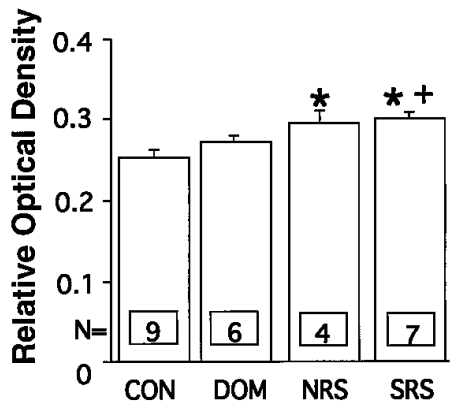

Figure 5. Population results of the relative optical density of CRF mRNA levels in the ACE across the behavioral groups. Values represent the mean $\pm \mathrm{SEM} ;{ }^{*} p<0.05$ versus $\mathrm{CON} ;{ }^{+} p<0.05$ versus DOM.

one administration (DeVries et al., 1985; Miller et al., 1989; Szot and Dorsa, 1994). 


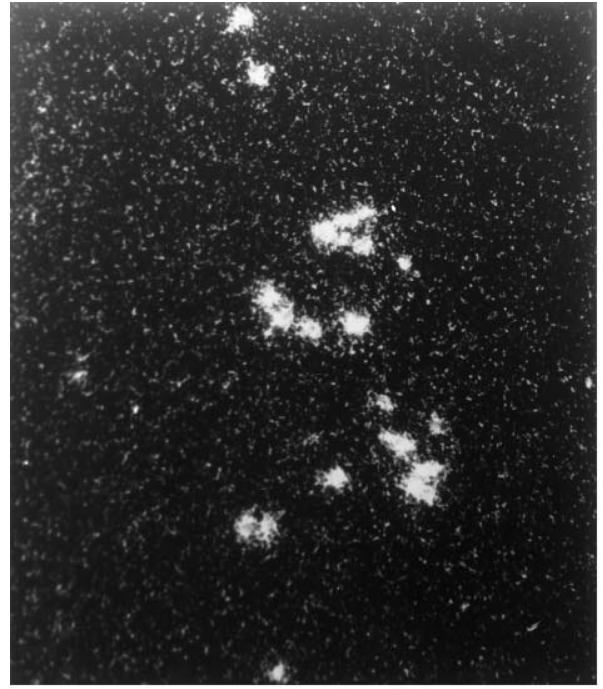

Control

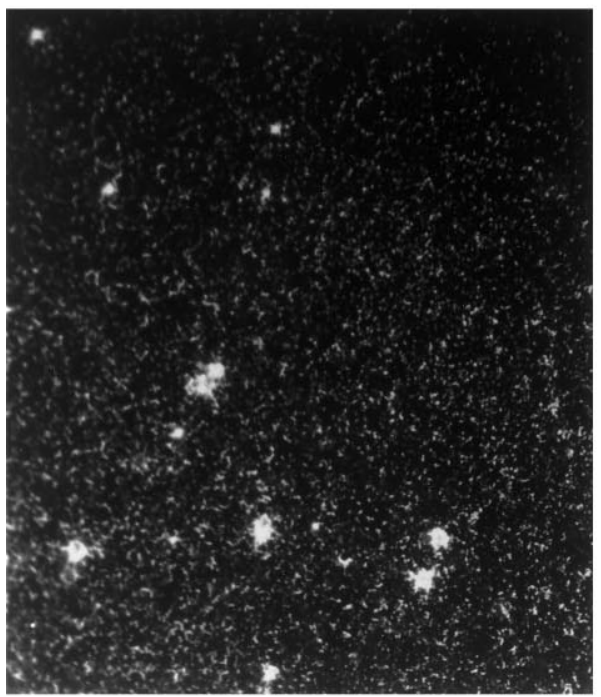

Non-Responder Subordinate

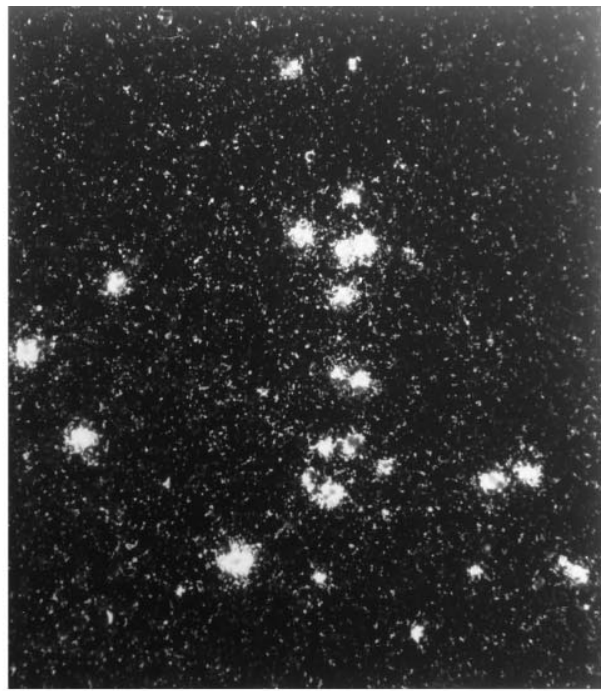

Dominant

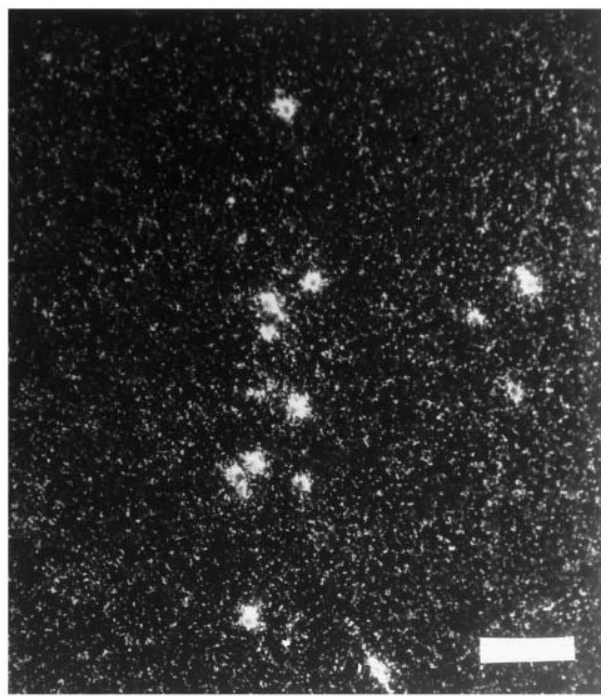

\section{Subordinate Responder}

Behaviors mediated by the vasopressinergic circuit arising from the AME include aggression (Koolhaas et al., 1990; Compaan et al., 1993), copulation (Smock et al., 1992), and social recognition (Lehman et al., 1980; Bolhuis et al., 1984; Bluthe et al., 1990). The decreased AVP expression in the AME may play a role in the reduction of aggressive and sexual behaviors in the subordinate animals after the stress-induced decline in testosterone secretion.

\section{Why are the NRS rats stress-nonresponsive and deficient in CRF mRNA in the PVN?}

The results presented here suggest that the failure of the NRS rats to mount a sufficient CORT response to the psychological stress of restraint may be attributable to a breakdown in HPA axis function at the level of the hypothalamus. Although AVP mRNA levels in the PVN did not vary as a function of behavioral rank, CRF mRNA was significantly altered after VBS housing. In two separate VBS experiments, the amount of CRF mRNA expressed per cell in the PVN was lower in NRS compared with DOM or SRS rats; in one experiment, the CRF mRNA per cell in NRS was lower than in CON rats as well. In experiment 1 , the number of CRF mRNA-positive cells in the PVN was also lower in the NRS compared with both the DOM and the SRS rats, but did not differ from that in the CON rats.

High levels of CRF mRNA expression are not necessary for rats to be able to show a stress-induced rise in plasma CORT, because the CON rats have CRF mRNA levels comparable with the NRS rats. The difference between these two groups is the chronic stress of the VBS affecting the HPA axis of the NRS rats. The rats that have experienced the chronic stress of the VBS and are still capable of showing a CORT response to a novel stressor (DOM and SRS rats) exhibit slightly elevated CRF mRNA expression in the PVN, whereas the NRS rats do not. This relative increase in CRF expression is consistent with that seen by others after both 

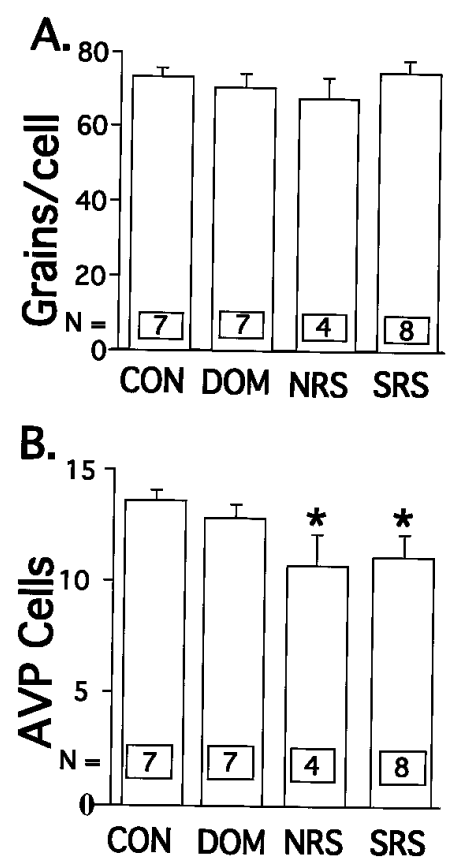

Figure 7. Population results showing AVP mRNA expression in the AME. $A$, Average number of AVP mRNA grains expressed per cell. $B$, Average number of AVP mRNA-labeled cells in the AME as a function of behavioral rank; * $p<0.05$ versus CON.

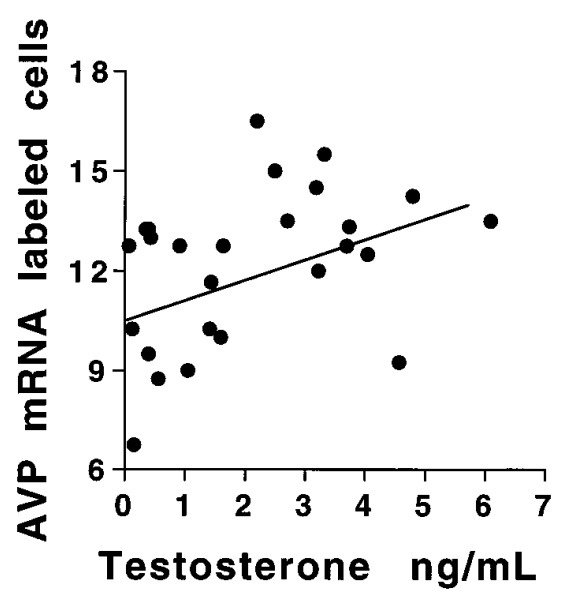

Figure 8. Number of AVP mRNA-labeled cells in the AME correlates with plasma testosterone level. Data from individual rats are charted showing the positive relationship between testosterone level and number of AVP mRNA cells in the AME $\left(Y=0.54 \times+11.05, r^{2}=0.153, F_{(1,24)}\right.$ $=4.32, p<0.05)$.

acute and chronic stress paradigms (Lightman and Young, 1988; Harbuz and Lightman, 1989; Makino et al., 1994, 1995) and probably helps maintain HPA function. The increase in CRF expression by DOM and SRS rats above control levels is likely to be attributable to the effects of chronic stress within the VBS, because all animals were given the acute restraint stress. The number or sensitivity of the CRF receptors in the pituitary may have decreased in response to chronic stimulation. Increased CRF release may be needed to overcome the effects of this downregulation. This hypothesis is supported by the observation that prolonged administration of CRF reduces the ACTH and CORT responses to a novel stressor (Tizabi and Aguilera, 1992). Another possible explanation might be an increased inhibitory input from GABA neurons that synapse on CRF neurons in the PVN (Herman et al., 1996). Additional studies are necessary to evaluate more fully the mechanisms underlying the NRS phenomenon.

Chronic high levels of glucocorticoids may be partially responsible for the low level of CRF mRNA in the NRS rats via negative feedback mechanisms. All behavioral ranks within the VBS show elevated CORT levels when blood is drawn immediately on removal from the VBS. Plasma CORT provides inhibitory feedback at CRF mRNA expression by acting directly on CRF-secreting neurons and via inputs to these neurons from the hippocampus. Because the NRS rats have the lowest levels of CORT-binding globulin in addition to elevated total CORT, free CORT is presumably highest in these animals. Thus, negative feedback inhibition is likely to be greatest in the NRS rat because of high free CORT combined with the lack of a downregulation in hippocampal type II glucocorticoid receptors that is observed in SRS rats (Chao et al., 1993).

Stress-induced increases in plasma CORT return to baseline faster in dominant rats than in subordinates. Only DOM rats showed statistically lower levels of plasma CORT in the prestress "Homecage" measurements and at the recovery time point in experiment 2. This suggests that the mechanisms responsible for terminating the HPA response are more efficient in the DOM than in the subordinates rats. In adrenalectomized rats, administration of the type II glucocorticoid receptor agonist RU 28362 has been shown to reduce CRF gene expression in the PVN (Albeck et al., 1994), whereas in intact rats, dexamethasone treatment reduces both basal and stress-stimulated levels of CRF mRNA (Lightman and Young, 1989), with the PVN implicated as a key site of dexamethasone action (Harbuz and Lightman, 1989). The hippocampus, an area that contains substantial concentrations of both type I and type II glucocorticoid receptor subtypes (McEwen et al., 1968; Reul and De Kloet, 1985), has been shown to play a role in the CORT-mediated containment of HPA responses (Jacobson and Sapolsky, 1991; Feldman and Conforti, 1980). As suggested above, inhibitory inputs from the hippocampus to the PVN (Herman et al., 1996) may be enhanced in NRS compared with SRS rats.

Neural inputs to the PVN from monoaminergic systems are also important regulators of CRF mRNA expression. The PVN receives innervation from the serotonergic and noradrenergic systems, both of which are stimulated in response to stress (Abercrombie and Jacobs, 1987; Vahabzadeh and Fillenz, 1994; McKittrick and McEwen, 1996) and have been implicated in the regulation of CRF release (Plotsky et al., 1989; Pan and Gilbert, 1992). Both of these systems are also modulated by chronic social stress in the VBS model (McKittrick et al., 1995; Watanabe et al., 1995), and differential regulation of these neurotransmitter systems may contribute to the differences in CRF mRNA expression seen among the NRS rats and other groups.

Many of the behavioral and endocrine changes in the subordinate rats are similar to those seen in humans with depressive illness. Both subordinate animals and depressed patients have lower overall activity levels and disrupted patterns of sleep, feeding, and sexual activity (Gold et al., 1988a; Blanchard et al., 1995). Function of the HPA axis is often dysregulated in depressed patients as well, because many exhibit elevated basal cortisol concentrations, impaired glucocorticoid feedback, and blunted responses to stimulation (Gold et al., 1988b; Pearson Murphy, 1991; Krishnan et al., 1993; Platt et al., 1994). Furthermore, regarding one specific aspect of our results, the lack of HPA stress 
response in NRS rats may be related to a phenomenon found in a subset of depressed human subjects, who show blunted responsiveness of their HPA axis (Platt et al., 1994; Kim et al., 1995). Additional study of the neurochemical changes associated with HPA dysfunction after chronic social stress may provide insight into the mechanisms responsible for similar changes in humans with depressive illness.

In conclusion, chronic psychosocial stress in the VBS is particularly stressful to subordinate rats, some of which show a progressive development of a paradoxical "Stress Nonresponsive" state characterized by reduced levels of CRF mRNA in the PVN in conjunction with impaired CORT responses to stress. We postulate that this state is the result of enhanced inhibitory input to PVN neurons attributable to increased glucocorticoid feedback or to increased inhibitory neural input.

\section{REFERENCES}

Abercrombie ED, Jacobs BL (1987) Single-unit response of noradrenergic neurons in the locus coeruleus of freely moving cats. I. Acutely presented stressful and nonstressful stimuli. J Neurosci 7:2837-2843.

Albeck DS, Hastings NB, McEwen BS (1994) Effects of adrenalectomy and type I or type II receptor activation on AVP and CRH mRNA in the rat hypothalamus. Mol Brain Res 26:129-134.

Armario A, Castellanos JM (1984) A comparison of corticoadrenal and gonadal responses to acute immobilization stress in rats and mice. Physiol Behav 32:517-519.

Berridge CW, Dunn AJ (1987) A corticotropin-releasing factor antagonist reverses the stress-induced changes of exploratory behavior in mice. Horm Behav 21:393-401.

Blanchard DC, Blanchard RJ (1990) Behavioral correlates of chronic dominance-subordination relationships of male rats in a seminatural situation. Neurosci Biobehav Rev 14:455-462.

Blanchard DC, Sakai RR, McEwen BS, Weiss SM, Blanchard RJ (1993) Subordination stress: behavioral, brain and neuroendocrine correlates. Behav Brain Res 58:113-121.

Blanchard DC, Spencer RL, Weiss SM, Blanchard RJ, McEwen BS, Sakai RR (1995) Visible burrow system as a model of chronic social stress: behavioral and neuroendocrine correlates. Psychoneuroendocrinology 20:117-134.

Bluthe RM, Schoenen J, Dantzer R (1990) Androgen-dependent vasopressinergic neurons are involved in social recognition in rats. Brain Res 519:150-157.

Bolhuis JJ, Fitzgerald RE, Dijk DJ, Koolhaas JM (1984) The corticomedial amygdala and learning in an agonistic situation in the rat. Physiol Behav 32:575-579.

Britton DR, Koob GF, Rivier J, Vale W (1982) Intraventricular CRF enhances behavioral effects of novelty. Life Sci 31:363-367.

Cador M, Ahmed SH, Koob GF, Le Moal M, Stinus L (1992) Corticotropin-releasing factor induces a place aversion independent of its neuroendocrine role. Brain Res 597:304-309.

Caggiula AR, Antelman SM, Aul E, Knopf S, Edwards DJ (1989) Prior stress attenuates the analgesic response but sensitizes the corticosterone and cortical dopamine responses to stress 10 days later. Psychopharmacology 99:233-237.

Chao HM, Blanchard DC, Blanchard RJ, McEwen BS, Sakai RR (1993) The effect of social stress on hippocampal gene expression. Mol Cell Neurosci 4:543-548.

Compaan JC, Buijs RM, Pool CW, De Ruiter AJH, Koolhaas JM (1993) Differential lateral septal vasopressin innervation in aggressive and nonaggressive male mice. Brain Res Bull 30:1-6.

DeVries GJ, Buijs RM, Van Leeuwen FW, Caffe AR, Swaab DF (1985) The vasopressinergic innervation of the brain in normal and castrated rats. J Comp Neurol 233:236-254.

Diamond DM, Bennet MC, Fleshner M, Rose GM (1992) Inverted U relationship between the level of peripheral corticosterone and the magnitude of hippocampal primed burst potentiation. Hippocampus 2:421-430.

Feldman S, Conforti N (1980) Participation of the dorsal hippocampus in the glucocorticoid feedback effect on adrenocortical activity. Neuroendocrinology 30:52-55.

Garcia-Marquez C, Armario A (1987) Chronic stress depresses exploratory activity and behavioral performance in the forced swimming test without altering ACTH response to a novel acute stressor. Physiol Behav 40:33-38.

Gold PW, Goodwin FK, Chrousos GP (1988a) Clinical and biochemical manifestations of depression: relation to the neurobiology of stress (Part 1 of 2). N Engl J Med 319:348-353.

Gold PW, Goodwin FK, Chrousos GP (1988b) Clinical and biochemical manifestations of depression: relation to the neurobiology of stress (Part 2 of 2). N Engl J Med 319:413-420.

Harbuz MS, Lightman SL (1989) Responses of hypothalamic and pituitary mRNA to physical and psychological stress in the rat. J Endocrinol 122:705-711.

Herman JP, Prewitt CM, Cullinan WE (1996) Neuronal circuit regulation of the hypothalamo-pituitary-adrenocortical stress axis. Crit Rev Neurobiol 10:371-394.

Jacobson L, Sapolsky RM (1991) The role of the hippocampus in feedback regulation of the hypothalamic-pituitary-adrenocortical axis. Endocrine Rev 12:118-134.

Kalin NH, Takahashi LK (1990) Fear-motivated behavior induced by prior shock experience is mediated by corticotropin-releasing hormone systems. Brain Res 509:80-84.

Katz RJ, Roth KA, Carroll BJ (1981) Acute and chronic stress effects on open field activity in the rat: implications for a model of depression. Neurosci Biobehav Rev 5:247-251.

Kim KD, Kim BL, Yu BH, Hong KS, Ritchie J, Austin S, Carroll BJ (1995) Rate-sensitive glucocorticoid feedback inhibition in normal humans and depressed patients. Soc Neurosci Abstr 21:873.

Koolhaas JM, van den Brink THC, Roozendaal B, Boorsma F (1990) Medial amygdala and aggressive behavior: interaction between testosterone and vasopressin. Aggress Behav 16:223-229.

Krishnan KR, Rayasam K, Reed D, Smith M, Chapell P, Saunders WB, Ritchie JC, Carroll BJ, Nemeroff CB (1993) The corticotropin releasing factor stimulation test in patients with major depression: relationship to dexamethasone suppression test results. Depression 1:133-136.

Lee EH, Tang YP, Chai CY (1987) Stress and corticotropin-releasing factor potentiate center region activity of mice in an open field. Psychopharmacology 93:320-323.

Lehman MN, Winans SS, Powers JB (1980) Medial nucleus of the amygdala mediates chemosensory control of male hamster sexual behavior. Science 210:557-560.

Lightman SL, Young WS (1988) Corticotropin-releasing factor, vasopressin and pro-opiomelamocortin mRNA responses to stress and opiates in the rat. J Physiol (Lond) 403:511-523.

Lightman SL, Young WS (1989) Influence of steroids on the hypothalamic corticotropin-releasing factor and preproenkephalin mRNA responses to stress. Proc Natl Acad Sci USA 86:4306-4310.

Magariños AM, McEwen BS (1995) Stress-induced atrophy of apical dendrites of hippocampal CA3c neurons: involvement of glucocorticoid secretion and excitatory amino acid receptors. Neuroscience 69:89-98.

Makino S, Gold PW, Schulkin J (1994) Corticosterone effects on corticotropin-releasing hormone mRNA in the central nucleus of the amygdala and the parvocellular region of the paraventricular nucleus of the hypothalamus. Brain Res 640:105-112.

Makino S, Smith MA, Gold PW (1995) Increased expression of corticotropin-releasing hormone and vasopressin messenger ribonucleic acid (mRNA) in the hypothalamic paraventricular nucleus during repeated stress: association with reduction in glucocorticoid receptor mRNA levels. Endocrinology 136:3299-3309.

McEwen BS, Weiss JM, Schwartz LS (1968) Selective retention of corticosterone by limbic structures in rat brain. Nature 220:911-912.

McKittrick CR, McEwen BS (1996) Regulation of serotonergic function in the CNS by steroid hormones and stress. In: CNS neurotransmitters and neuromodulators: neuroactive steroids (Stone TW, ed), pp 37-76. Boca Raton, FL: CRC.

McKittrick CR, Blanchard DC, Blanchard RJ, McEwen BS, Sakai RR (1994) Behavioral and endocrine consequences of fluoxetine intervention in a model of social stress. Soc Neurosci Abstr 20:18.

McKittrick CR, Blanchard DC, Blanchard RJ, McEwen BS, Sakai RR (1995) Serotonin receptor binding in a colony model of chronic social stress. Biol Psychiatry 37:383-393.

Miller MA, Urban JH, Dorsa DM (1989) Steroid dependency of vasopressin neurons in the bed nucleus of the stria terminalis by in situ hybridization. Endocrinology 125:2335-2340.

Minerbo G, Albeck D, Goldberg E, Lindberg T, Nakari M, Martinez C, Garritano J, Smock T (1994) Activity of peptidergic neurons in the 
amygdala during sexual behavior in the male rat. Exp Brain Res 97:444-450.

Ottenweller JE, Natelson BH, Pitman DL, Drastal SD (1989) Adrenocortical and behavioral responses to repeated stressors: toward an animal model of chronic stress and stress-related illness. Biol Psychiatry 26:829-841.

Ottenweller JE, Servatius RJ, Tapp WN, Drastal SD, Bergen MT, Natelson BH (1992) A chronic stress state in rats: effects of repeated stress on basal corticosterone and behavior. Physiol Behav 51:689-698.

Pan L, Gilbert F (1992) Activation of 5-HT1A receptor subtype in the paraventricular nuclei of the hypothalamus induces CRH and ACTH release in the rat. Neuroendocrinology 56:797-802.

Pavlides C, Watanabe Y, Magariños AM, McEwen BS (1995) Opposing roles of type I and type II adrenal steroid receptors in hippocampal long-term potentiation. Neuroscience 68:387-394.

Paxinos G, Watson C (1982) The rat brain in stereotaxic coordinates. Sydney: Academic.

Pearson Murphy BE (1991) Steroids and depression. J Steroid Biochem Mol Biol 38:537-559.

Platt JE, Simkowitz P, Silva R, Schwitzer J, Friedhoff AJ (1994) Responsiveness to stress in major depression. Program and Abstracts, First World Congress on Stress 1:69.

Plotsky PM, Cunningham Jr ET, Widmaier EP (1989) Catecholaminergic modulation of corticotropin-releasing factor and adrenocorticotropin secretion. Endocr Rev 10:437-458.

Reul JMHM, De Kloet ER (1985) Two receptor systems for corticosterone in rat brain: microdistribution and differential occupation. Endocrinology 117:2505-2511.

Sapolsky RM (1985) Stress-induced suppression of testicular function in the wild baboon: role of glucocorticoids. Endocrinology 116:2273-2278.

Sapolsky RM, Krey LC, McEwen BS (1985) Prolonged glucocorticoid exposure reduces hippocampal neuron number: implications for aging. J Neurosci 5:1222-1227.

Schmale H, Heinsohn S, Richter D (1983) Structural organization of the rat gene for the arginine vasopressin-neurophysin precursor. EMBO J 2:763-767.

Sherman JE, Kalin NH (1986) ICV-CRF potently affects behavior without altering antinociceptive responding. Life Sci 39:433-441.

Sirinathsingihi DJ, Rees LH, Rivier J, Vale W (1983) Corticotropinreleasing factor is a potent inhibitor of sexual receptivity in the female rat. Nature 305:232-235.
Smock T, Arnold S, Albeck D, Emerson P, Garritano J, Burrows K, Derber W, Sanson C, Marrs K, Weatherly H, Kruse K (1992) A peptidergic circuit for reproductive behavior. Brain Res 598:138-142.

Swiergiel AH, Takahashi LK, Kalin NH (1993) Attenuation of stressinduced behavior by antagonism of corticotropin-releasing factor receptors in the central amygdala in the rat. Brain Res 623:229-234.

Szot P, Dorsa DM (1994) Expression of cytoplasmic and nuclear vasopressin RNA following castration and testosterone replacement: evidence for transcriptional regulation. Mol Cell Neurosci 5:1-10.

Taché Y, Ducharme JR, Haour F, Saez J, Collu R (1980) Effect of chronic intermittent immobilization stress on hypophysio-gonadal function of rats. Acta Endocrinol 93:168-174.

Thompson RC, Seasholtz AF, Herbert E (1987) Rat corticotropinreleasing hormone gene: sequence and tissue-specific expression. Mol Endocrinol 1:363-370.

Tizabi Y, Aguilera G (1992) Desensitization of the hypothalamic-pituitaryadrenal axis following prolonged administration of corticotropin-releasing hormone or vasopressin. Neuroendocrinology 56:611-618.

Urban JH, Miller MA, Dorsa DM (1991) Dexamethasone-induced suppression of vasopressin expression in the bed nucleus of the stria terminalis and medial amygdala is mediated by changes in testosterone. Endocrinology 128:109-116.

Vahabzadeh A, Fillenz M (1994) Comparison of stress-induced changes in noradrenergic and serotonergic neurons in the rat hippocampus using microdialysis. Eur J Neurosci 6:1205-1212.

Watanabe Y, McKittrick CR, Blanchard DC, Blanchard RJ, McEwen BS, Sakai RR (1995) Effects of chronic social stress on tyrosine hydroxylase mRNA and protein levels. Mol Brain Res 32:176-180.

Weiss JM, Goodman PA, Losito BG, Corrigan S, Charry JM, Bailey WH (1981) Behavioral depression produced by an uncontrollable stressor: relationship to norepinephrine, dopamine, and serotonin levels in various regions of rat brain. Brain Res Rev 3:167-205.

Wheeler GD, Wall SR, Belcastro AN (1984) Reduced serum testosterone and prolactin levels in male distance runners. JAMA 252:514-516.

Winslow JT, Hastings N, Carter CS, Harbaugh CR, Insel TR (1993) A role for central vasopressin in pair bonding in monogamous prairie voles. Nature 365:545-548.

Woolley CS, Gould E, McEwen BS (1990) Exposure to excess glucocorticoids alters dendritic morphology of adult hippocampal pyramidal neurons. Brain Res 531:225-231. 